A Journal for Language Learning Tydskrif vir Taalaanleer

\title{
ENHANCING CRITICAL MULTICULTURAL LITERACY AMONGST PRE- SERVICE TEACHERS (PSTS) IN A BACHELOR OF EDUCATION PROGRAMME
}

Omar Esau

Stellenbosch University

In this article I reflect on how I attempted to inculcate and enhance critical multicultural literacy in my Bachelor of Education classroom. Critical multicultural literacy educators focus not only on curtailing bias and inequity in the classroom, but also on promoting social justice in society at large. In this article I argue that the development of critical literacy promotes social justice and the exploration of language and literature in many forms. Using a grounded theory approach, I analyse data sources, including interviews, focus group discussions and questionnaires. Findings suggest that exposing pre-service teachers critically to multicultural literacies develops and nurtures much needed social consciousness and social justice in future educators. From an action research perspective, I also discuss implications for future practice.

\section{Keywords}

Bachelor of Education programme; critical multicultural literacy; pre-service teachers; action research

\section{INTRODUCTION}

One of the goals of higher education is to prepare students for participation in civic life (Iverson \& James, 2010). Many students from mono-cultural backgrounds have very little experience of co-constructing knowledge with peers from 'other' cultural and linguistic backgrounds. For pre-service teachers (PSTs) a lack of multicultural exposure and understanding of multicultural communication is a major shortcoming, as it is almost certain that they will have to teach multicultural classes and work together with teachers from different cultural and linguistic backgrounds.

In this article I analyse the potential that critical multicultural literacy holds for pre-service teachers, enabling them to become critically reflective and socially conscious as future educators in a multicultural and diverse society. More than merely exposing them to a module of multicultural education, I wanted to stimulate and encourage them to become more critical, imaginative and argumentative as pre-service teachers, and to nurture more caring and sharing amongst them (ubuntu), and to develop and enhance their sense of inclusivity. By inclusivity I mean a multicultural awareness of and sensitivity to diversity. For instance, I would like the PSTs to learn to think of all learners irrespective of their cultural backgrounds as inclusive of the current South African education landscape.

Although we know that teaching must involve deep caring for learners (including their families and communities), we also know that the life experiences of many PSTs themselves have not adequately prepared them for the immense challenges inherent in living in a 
multicultural and diverse society. The majority of the PSTs are white middle-class Christian students with a minority of black students, some coming from poor and non-Christian backgrounds. Given the increasingly diverse cultural communities emerging in South Africa, enhancing knowledge of other cultures and practices will better prepare teachers to serve the needs of all students. Theoretically speaking, one's culture is one's overall way of life informed by beliefs and customs. I borrow McLaren's (1988) understanding of culture, when he says that culture signifies the particular ways in which a social group lives out and makes sense of its given circumstances and conditions of life.

In our multicultural classrooms there are children who don't have the basic necessities of life such as food and shelter; they come from unstable homes, or adhere to practices that are not 'mainstream' in terms of, say, religious practices and political persuasions, in addition there are immigrants as well as children from low socioeconomic backgrounds, irrespective of socalled race, living with the threat of diseases and illnesses, children with disabilities and children who bully, to give just a few examples.

In this context teaching pre-service teachers (PSTs) the literacy skills of reading, writing and understanding texts involves teaching them much more than merely meeting the basic needs of the learners mentioned above. It involves planning and teaching and learning a sociocultural perspective on the curriculum that involves both critical literacy and multicultural literacy.

Critical multicultural literacy instruction that challenges discrimination and intolerance, as embodied in language practices specifically, becomes increasingly crucial to promote educational equity and social justice for all students (Ukpokodu, 2008). In this article I use the term 'critical multicultural literacy instruction' to describe a pedagogy that combines an emphasis on critical literacy (Stevens \& Bean, 2007) with the notion of a culturally responsive pedagogy (Ladson-Billings, 1995). When blended, the two conceptualisations overlap with the construct of critical multicultural education (May, 1999).

For that reason I use a broader term 'critical multicultural literacy' to describe the topical focus in this action research study. For the purposes of this paper I ask the following research question: What can be learned from enhancing critical multicultural literacy amongst preservice teachers (PSTs)?

\section{PERSPECTIVES ON CRITICAL MULTICULTURAL LITERACY IN THE LITERATURE}

The theoretical work of Barton, Hamilton and others (2000) based at the Lancaster Literacy Research Centre in the United Kingdom has been particularly influential in developing theories of literacy as a social practice. In answer to the question "What is literacy?" theorists of literacy as a social practice would say that literacy is what people do with reading, writing, and texts in real-world contexts and why they do it: Barton and Hamilton (2000: 7) note that in the simplest sense "literacy practices are what people do with literacy". They caution, however, that practices involve more than actions with texts; practices connect to, and are shaped by, values, attitudes, feelings and social relationships. Social relationships are crucial, as "literacy practices are more usefully understood as existing in the relationships between people, within groups and communities, rather than as a set of properties residing in individuals" (Barton \& Hamilton, 2000: 8). 
Current research and perspectives define literacy within a sociocultural context. Literacy is defined not just as the multifaceted act of reading, writing and thinking, but as constructing meaning from printed or digital texts within a sociocultural context (Barton \& Hamilton 2000; Erikson, 1984; Gee 2000; Street 1995).

Sociocultural perspectives on literacy are related to sociolinguistic conceptualisations of the ways in which language instantiates culture (Gee, 1996; Halliday, 1973), the ways in which language varies according to contexts (Bakhtin, 1986), the relationship between language use and power (Bourdieu, 1979), and the ethnography of communication (Hymes, 1996). In this paper I draw on these sociocultural perspectives and use them in ways that suit the culture and contexts in which the Stellenbosch pre-service teachers and their prospective learners may find themselves.

Although it is essential that all students acquire basic skills in literacy, I believe this is not sufficient in our diverse and troubled world. Literate citizens in a diverse democratic society should be reflective, moral and active citizens in an interconnected global world. They should have the additional knowledge and critical skills to make the world a more just and safer place to live in. The world's greatest problems stem not only from people being unable to read and write and do mathematics, but rather how these citizens can apply their literacy skills to make the world a more peaceful and better place for all. In addition to mastering basic reading and writing skills, literate citizens in democratic multicultural societies such as the United States, Canada, South Africa and globally should develop critical multicultural literacy (Banks, 2003).

Multicultural literacy consists of the skills and abilities to identify the creators of knowledge and their interests (Banks, 1996), and to exploit the assumptions of knowledge to guide action that will create a humane and just world. Paulo Freire (1970), in Pedagogy of the Oppressed, states that we must teach students to read the word and the world. Reading the word requires basic knowledge and skills. However, reading the world requires students to question the assumptions of institutionalised knowledge and to use knowledge to take action that will make the world a just place in which to live and work. When we teach students how to critique the injustice in the world, we should help them to formulate possibilities for action to change the world to make it more democratic and just. Critique without hope may leave students disillusioned and without agency.

The term 'critical literacy' was developed by social critical theorists concerned with dismantling social justice and inequalities. Freire (1970) proposes a system in which students become more socially aware through a critique of multiple forms of injustice. Edward Behrman (2006) explains that the development of critical literacy promotes social justice and the exploration of language and literature in many forms. Behrman suggests that the specific types of lessons examine power relationships that are found in language and literature, and that these practices show students that language is never neutral. Successful integration of multicultural literature starts with the classroom teacher. The teacher must introduce learners to concepts of justice, fairness, equality and living in harmony with others who might not have similar backgrounds or even ideas. The teacher must believe that multicultural literacy can make a difference. Ladson-Billings (1995) says teachers need to have "an interest and a desire" to teach minority students and make cultural studies a part of their learning environment (p. 131). What makes this particularly relevant to the context where I teach is that the majority of the PSTs are white middle-class students who adhere to the Christian faith. They are, however in the minority in the country and their challenge is to co-exist with 
the majority of the people who don't have the same cultural background and cultural capital. Since the majority of the students adhered to Christian faiths, so they were encouraged to research and observe a non-Christian religion.

Multicultural literacy education includes making teaching and learning more equitable in the classroom by serving the needs of students from diverse racial and ethnic backgrounds. This can be done by incorporating multicultural literature, and by bridging home and school literacy practices. These goals, at the very least, should lie at the heart of a culturally relevant pedagogy. However, critical multicultural education goes beyond the basic tenets of multicultural education by taking into account the operation of power, privilege and oppression as reflected in and shaped by literacy practices. In addition, critical multicultural literacy educators focus not only on curtailing bias and inequity in the classroom, but also on promoting social justice in society at large (Ladson-Billings, 1995; Stevens \& Bean, 2007). Here, I am reminded by Waghid (2011: 395) that social justice education is not just about teaching the students deliberative argumentation and the recognition of difference and otherness. Students must be taught what it means to act with compassion and imagination, because imaginative action seems to be desirable in promoting civic reconciliation - a practice necessary to building relations of care, justice and trust in universities.

The use of multicultural literature can also extend students' knowledge about parallel cultures by exposing them to the differences and similarities between their own culture and that of other groups (Norton, 1983). These observations, documented in research, support the notion that incorporating multicultural literature into the curriculum can expand students' awareness and decrease negative stereotyping of individuals from other cultures (Litchner \& Johnson, 1973). Literature can present students with clear contrasts in perspectives and can help them to understand their own cultural heritage and that of others - within and outside the classroom (Rasinski \& Padak, 1990).

Because critical literacy is embodied differently in every classroom, based on the subject matter and the student population, there is no formula for the way that teachers should engage students in developing their mastery of critical literacy; however, there are some practices that appear more commonly in lessons than others. Behrman (2006) maintains that developing a pedagogy that includes critical literacy is an organic process that continually needs to be revisited and refined.

Although there are many ways to prepare teachers to become critical multicultural educators, I felt that my Bachelor of Education classroom, where I had to teach my students multicultural and multi-religion education, provided the ideal space to conduct my action research project. I also heeded Sims-Bishop's (1997) advice to teachers to be aware of potential conflicts that can arise when students of multicultural backgrounds share classrooms; encouraging teachers to be circumspect in order to avoid creating difficult situations.

During the academic year of 2012 I engaged the prospective teachers in a compulsory group work research project as an assignment in the multicultural and multi-religion module in the Bachelor of Education course in the Faculty of Education at the University of Stellenbosch. One hundred and seventy students registered for the module and the class was divided into groups of 6-8 students for the group projects. 
As already pointed out, this research was informed by theoretical and applied work in the areas of critical literacy and critical multicultural education. My work was also grounded in social-constructivist learning theory. Vygotsky's (1978) social-constructivist learning theory posits that learning stems from social interaction. Knowledge emerges through participating in the practices of the group, from observing the thinking of more experienced others, from joint sharing of cultural artefacts and tools, and from receiving socially mediated support.

\section{NEGOTIATIONS AND ETHICAL CONSIDERATIONS}

Before I commenced with my project I felt that it would be ethical to discuss my work with the students and negotiate around this with the various participants involved in my research project. As Ely (1999:218) points out: "Qualitative research is an ethical endeavour." I could not possibly claim to be empowering the students if I did not involve them at the start of the research process. Whilst ethics can be viewed as requiring ethical behaviour towards the participants in my project, it also commits us to mutual respect and not to do harm (Whitehead \& McNiff, 2006). To participate in this study, all participants were asked to give their informed consent. Apart from having the option of opting out at any time, the participants were assured of anonymity in my report on this study. Although they all agreed, I nevertheless questioned them as to why they were willing to engage in the research deliberations in class. Their responses were important, as I saw them as being key participants in the project. These are some of the remarks:

\section{- $\quad$ Projects are exciting and make class interaction interesting; \\ - $\quad$ Projects involving social upliftment make one more matured; \\ - $\quad$ Reflecting on action improves practice; \\ - $\quad$ Discussing the way we think about things improves thinking about things.}

These comments by the students concerning their involvement in the project convey much more than simply a "yes" answer. Besides giving the researcher a clearer notion of what the students want, they also go a long way towards clearing the conscience of the researcher. It was conveyed to the students that as co-researchers they had to be actively involved in conceptualising and designing the project, as well as in collecting and analysing the data. They had to be prepared to be interviewed by stakeholders such as the teachers, learners and principals, complete questionnaire forms, keep a diary and, if they were comfortable about it, to hand in their diaries to be scrutinised and analysed at the end of the project.

Ethics is concerned with how one treats the individuals with whom one interacts and is involved with (Mathison, Ross \& Cornett, 1993). I was, however, cognisant of the point in Chevalier and Buckles (2013) that norms and ethical conduct and their implications may have to be revisited as the project unfolds.

\section{METHODOLOGY AND DATA COLLECTION}

The research methodology used for collecting my data was qualitative and interpretive. Interpretivism aims to move away from obtaining knowledge through experimental manipulation of human subjects towards achieving understanding by means of conversations with subjects. Social reality is viewed as socially constructed on the basis of a constant process of interpretation and reinterpretation of the internal, meaningful behaviour of people (Denzil \& Lincoln, 2000: 92). The data-collection methods used included my field notes, interviews, questionnaires and focus group interviews. In this research project the focus 
group technique was especially useful. It seems to be one of the most effective qualitative methods for studying ideas in group contexts. In particular, it can explore group interaction, attitudes, cognition and hypothesis formation, and arrive at a synergy of ideas because the whole is greater than the sum of the parts (Zuber-Skerritt, 2012: 68). The informal discussions and unstructured interviews conducted with students focused primarily on asking them to elaborate on their experiences related to reading and interpreting multicultural literacy texts. The students' comments were noted in the researcher's journal for analysis and reflection as part of the action research cycle. The questionnaires were particularly useful to extract feedback on the students' excursions and presentations in the classroom. The student assistant, who was an action research master's student, provided me with valuable feedback regarding the research projects of the Bachelor of Education students. Besides commenting that topics chosen by pre-service teachers were interesting and refreshing, she also contributed significantly to the analysis of the constraints faced by the pre-service teachers, which included the difficulties and hindrances they were exposed to. I had two focus group sessions with four student volunteers. Two discussions were held lasting roughly 30 minutes each. The first focus group meeting was at the mid-point of the module to review progress and learning, and to gather suggestions for improvement. The second discussion was at the end of the module and sought particularly to evaluate and analyse which aspects of the project could be improved.

\section{PROJECT GUIDELINES AND PROCEDURES}

Classrooms are currently undergoing enormous change as school populations become increasingly heterogeneous. Consequently, the goals of this project were:

a) to expose pre-service teachers to "other" cultures and religions and to enhance their awareness of diversity and inclusivity. (The majority of the students adhered to Christian faiths; so they were encouraged to research and observe a non-Christian religion); and

b) to develop critical multicultural and imaginative future teachers with a keen sense of sharing and caring for each other and for others (ubuntu).

For the PSTs the project comprised of an excursion report and class presentation. They also had to utilise the reading material given in the class to substantiate their reports and class presentations. The text below provides an outline and a guide for the expected excursion reports and presentations for the multicultural module. 


\section{EXCURSION REPORTS INSTRUCTIONS}

Students will, in their assigned groups, visit the centre of a non-Christian religion to observe their worship and religious rituals. Groups are to arrange their visits themselves. The visit must be to one of the world religions. Suitable centres include but are not limited to:

Non-Christian Centres:

A Jewish Synagogue: See http://www.gardensshul.org/

An Islamic Mosque: See http://www.muslim.co.za/mosques.sa.htm

A Bahai Centre: See http://www.bahai.org.za/cm/node/306

A Hindu Centre: Shree Paraasakthie Aalayam (Divine Cultural Centre) - Cnr. York \& Jasmine Street Cravenby Estate Cape Town.

A Hari Krishna Temple: 17 St. Andrews Road, Rondebosch, capetown@pamho.net Rastafarianism

African Independent/African Initiated Churches (Including Zionist Churches)

Following each visit to the chosen centre, a 1000 word report must be submitted by each student. While visitation is to be done as a group, reports are individual projects. Each report should cover:

1) A brief history of the chosen group - with emphasis on its presence in South Africa

2) A brief outline of the group's beliefs

3) A brief outline of the group's major festivals and celebrations

4) A personal reflection on your visit

\section{PRESENTATIONS}

Students will work in their assigned groups to prepare a 20-minute oral presentation. Students are to research, prepare and present a 15- to 20-minute tutorial presentation entitled, "Life as a..." The tutorial will be based on an individual who is a follower of one of the non-Christian religions. The purpose of the tutorial presentation is to provide the class with a "through-my-eyes" experience that enhances our appreciation of what it is like to be a member of another world religion.

To help develop class understanding of other religions, some attempt should be made to involve the class members in some practical activity relating to the world religion, e.g. performing a typical ritual, acting out a worldview-specific practice, role playing a religious activity, etc. Time should also be allowed for student reaction, questions and discussion. The students' presentations will be assessed on content, creativity, presentation effectiveness, and ability to create an informed awareness of life within other world religions. A printed synopsis of the tutorial presentation must be distributed to the class before each presentation. At least 6 sources should be listed as references. 
To make the aims of the project clear, I had to give the PSTs clear instructions for their excursion reports and the subsequent class and group presentations. As mentioned earlier, the class was divided into groups of 6-8 students for the group projects. It is interesting to note the topics selected by the various PSTs as they really committed themselves to their critical multicultural projects. The students formulated their own topics and the list that follows details some of these topics:

- Why learn about religious and spiritual traditions?

- Multi-religion and multiculturalism

- Religious diversity in schools

- Connecting world religions through storytelling

- Poetry and songs in African Traditional Religion

- Understanding the teachings of Hinduism

- Women in Islam

- Understanding the teachings of Buddha

- Christianity - Orthodoxy and Catholicism

- The Jewish holy days, festivals and celebrations

\section{FINDINGS}

The findings relating to the conditions under which students study, how students engaged with their assigned projects and students' interaction with others in the learning environment are discussed below. The findings of the study also give an overall perspective on the developmental needs of pre-service teachers who are acquiring critical multicultural literacy in the rapidly changing knowledge economy of South Africa. In my own reflection I realised that most of my time and energy spent on preparation and especially post-lecture feedback for students far exceeded the actual instruction time allocated for the module. I often wondered whether this critical multicultural literacy project was too complex for the students. However, their motivation and enthusiasm gave me a sense of achievement.

\section{Observations}

When first confronted with the research project, most students appeared rather apprehensive about tackling the task. Students in their assigned groups had to visit, observe and interact with religious centres that they were not familiar with. This was taking them outside of their familiar surroundings, such as their own religious affiliation and language group. After making their initial contact, most of them became more enthusiastic and saw the benefit of moving outside the university environment of the BEd programme.

\section{Perceptions of critical multicultural literacy}

The classroom atmosphere was generally relaxed and conducive to interaction between students and the lecturer, as well as between the students themselves. The researcher encouraged the students - as a class, in groups and individually - to share their opinions of their research project experiences, and the techniques and strategies they use when engaging with another cultural and religious context. These discussions revealed the students' perceptions of, and thoughts on, multicultural literacy. In their discussions it became evident that the students were more prepared to take up the challenge to choose a disadvantaged or even dysfunctional school during their annual practice teaching sessions in local schools. 
They were more prepared to take up the challenge to teach in a classroom with less state-ofthe-art apparatus compared to an upper-middle-class school that had "all the cosmetics" (as one group expressed it). These types of responses were important for me, as they indicated that the PSTs were becoming what Waghid (2011: 395) described as students willing to act with compassion and imagination in building relations of care and justice (ubuntu) towards the other.

Students reported that it was indeed worthwhile to learn about multicultural issues and critical literacy. Multicultural education focuses on teaching tolerance and accepting differences. Critical literacy promoted the examining of various texts, such as the reading material given in the module, through a critical lens, taking into account multiple perspectives and applying them in their projects.

Below are some comments (18 May 2012) that illuminate the data categories on critical multicultural literacies. I believe that these comments strongly suggest that the project did indeed develop and enhance cultural awareness and sensitivity amongst the PSTs.

This project definitely made me aware of the importance of human rights. In my project I focussed on Religious Beliefs and Freedom of Speech. This, I believe is the cornerstones of being a human being.

There are different religious beliefs and other cultures, and one must respect the religious beliefs of others. Respecting other religions and their belief systems strengthens one's own belief as well. Being tolerant of any other religious belief besides your own makes you a more "rounded" human being.

Freedom of speech is the essence of democracy. Once your voice is taken away from you, then your human rights also disappears. After interviewing a Muslim woman about Islam, I received another perspective. Looking at our country, South Africa's constitution is amongst the most democratic constitutions in the world. Trying to live according to our constitution remains the ultimate challenge to us all.

\section{DISCUSSION}

The themes that emerged from the analysis of the data related to students' individual reactions, perceptions and experiences in relation to their research, projects, site visitations, interaction and engagement with others, as well as to the factors that inhibit or aid the enhancement of critical multicultural literacy. Three themes in particular emerged from the analysis of the data.

First, the pre-service teachers were able to engage with other cultural groups and co-construct knowledge with their peers. I was impressed and intrigued by the diversity and the scope of the research questions that the students formulated. At the end of the final semester students wrote their final papers on their journey of learning about their assigned cultural group project. Most of the students felt that their research projects made them more socially responsive to social justice issues. Some of them never realised how other religions and cultures were being side-lined or merely disregarded. Thus, exposing pre-service teachers critically to multicultural literacies develops and nurtures much needed social consciousness and social justice in future educators. Most students found the process to be helpful and 
planned to do critical multicultural literacy programmes in their future classrooms and immediate communities.

Second, pre-service teachers' projects focused on meeting the teaching and learning needs of all the learners in their respective classrooms. PSTs used this class assignment to inform their teaching practices in particular classroom situations during school visits/teaching practice, which they found culturally challenging to address. Most student teachers reflected on how they were able to understand their teaching practices more fully by engaging in this project. Each of the student teachers recognised the potential of using their new literacy skills as a means of exploring how to improve their teaching practice based on the particular contexts and needs of their learners. One student emphasises how her multicultural literacy project impacted on her practice teaching:

When I visited the mosque during my project, I realised the importance of wearing the head scarf for Muslims, I could understand why it was important for these learners to wear scarfs in my classroom during my practice teaching.

Finally, it was evident that some of the research projects were not without challenges. This was also evident from the comments of my student assistant and from the feedback I received from students in the Bachelor of Education programme. Amongst the comments of the student assistant were the following:

- Some of the research projects are too over-ambitious; In their quest to be inclusive some PSTs became too involved in their centre and school visitations and wanted to tackle too many issues;

- Time constraints, as some of the projects seemed too extensive.

The need for more time to complete the project that included a visit to a religious centre, a report and a class presentation was also emphasised in the focus group discussions, which prompted the idea that the multicultural project needed to be smaller and more manageable. Another limitation of the project was that the pre-service teachers involved were at different levels of understanding critical multicultural literacy. It was evident in some of their projects that some students had no grasp, or only a very limited understanding, of what multicultural research entails, as they did not see the need to move beyond their comfort zones. This could be because of a lack of confidence to express their opinions or viewpoints, and to explore alternative interpretations, or an inability to critically re-imagine or reflect more deeply. Some PSTs clearly indicated in their discussions that they don't see the need to understand other cultures, as they were already preoccupied with their own. They also felt that it was not their duty to make learners sensitive to inclusivity or to respect other cultures as this should be instilled at home.

What became clear from the deliberations with the PSTs and the student assistant and from my own reflections was that exposing pre-service teachers critically to multicultural literacies develops and nurtures much needed social consciousness and social justice in future educators. According to some of the pre-service teachers, the multicultural module changed not only the way they thought about or perceived the other cultures and practices they encountered, but most importantly their outlook as future teachers. Together the community of pre-service teachers, student assistant and I as teacher-educator found new ways in which to think about schools and schooling, that is, new ways in which to think about the work of teaching and learning, and about teaching in a rapidly changing heterogeneous South Africa. 


\section{IMPLICATIONS FOR PRE-SERVICE TEACHER EDUCATION}

For all of us, and here I include the student assistant, this action research project was significant because it provided us with evidence that action research, if done collaboratively and in a participatory way, can empower pre-service teachers by giving them the tools to become effective practitioner social justice researchers. I believe that this type of empowerment drawing on the whole theme of enhancing social justice and sharing and caring for each other gave the PSTs some confidence about their future. Also, the project enhanced the students' multicultural experience and bridged the theory-practice divide in that we integrated the university classroom with the community cultural centres. This was evident in the majority of the PST's responses. For example, the groups responded as follows:

Working in groups and sharing our experiences made us more conscious of other cultures and their way of thinking and behaving.

I would never have been so brave to just go and talk about sensitive religious issues on my own at that center.

We have become much more critically aware of how others live and practice their beliefs.

Simultaneously, by modelling collaborative action research, we grew professionally ourselves. Given our action research stance (Kemmis \& McTaggart, 2005; Whitehead \& McNiff, 2006), conducting this research helped us to focus on the aspects of teaching we would change in future iterations of this required graduate-level course on multicultural and multi-religious education.

With respect to the significance of this research for pre-service education, analysing the final reports indicated to me that pre-service teachers are capable of selecting and carrying out projects beneficial to their future learners. Furthermore, they indicated their enjoyment in choosing an issue that was significant for them as well as the satisfaction they derived from the implementation and analysis of their project; they also indicated that they intend to actively research their own practice and maintain their constant awareness of being agents for social change and uplifting the disadvantaged and oppressed. This was especially satisfying to me, as the majority of my students came from privileged backgrounds. Most of all, the preservice teachers felt empowered as active agents in their own professional development.

\section{CONCLUSION}

Finally, although this action research project with an emancipatory agenda to enhance critical multicultural literacy amongst candidate teachers (PSTs) may not be a magical cure for all that ails education, it can become a powerful tool supporting the transformation of our society in a very uncertain $21^{\text {st }}$ century. My optimism comes from my personal experience and the inquiry I undertook and still try to implement as a teacher-researcher. As a teacher-educator, I am encouraged by the students' responses. I believe this critical multicultural literacy project has made a significant contribution to the empowerment of pre-service teachers in our programme and I hope this sense of efficacy will extend to their future classroom practice and so develop more socially conscious and socially just teacher-researchers. 


\section{REFERENCES}

BAKHTIN, M.M. 1986. Speech genres and other late essays (C, Emerson \& M, Holquirst Eds.): (V W McGee, Trans.). Austin: University of Texas Press.

BANKS, J.A. 1996. Multicultural education, transformative knowledge and action: Historical and contemporary perspectives. New York: teachers College Press.

BANKS, J.A. 2003. Teaching strategies for ethnic studies. Boston: Allyn and Bacon.

BARTON, S., \& M. HAMILTON. 2000. Literacy practices. In: Barton, D., Hamilton, M \& Ivanic, R. (Eds.). Situated literacies: reading and writing in context. London: routledge. Pp.7-15.

BEHRMAN, E. 2006. Teaching about language, power, and text: A review of classroom practices that support critical literacy, Journal of Adolescent and Adult Literacy 49:6, pp. 490-98.

BOURDIEU, P. 1979. Distinction: A social critique of the judgement of taste. Cambridge, MA: Harvard University Press.

CHEVALIER, JM., \& DJ. BUCKLES. 2013. Participatory Action Research: Theory and Methods for Engaged Inquiry. St John University, York, UK: Routledge.

DENZIN N.K., \& Y.S. LINCOLN. 2000. Handbook of Qualitative Research. London: Sage.

ELY, M. 1999. Doing qualitative research: Circles within circles. London: Falmer Press.

FREIRE, P. 1970. Pedagogy of the oppressed. Harmondsworth: Penguin.

GEE, J.P.2000. "The New Literacy Studies; form "socially situated' to the work of the social' in Barton, D., Hamilton, M. and Ivanic, R. 2000 Situated Literacies: reading and writing in context. Routledge: London. Pp.180-196.

GEE, J.P. 1996. Social linguistics and literacies: Ideology in Discourses (2nd ed.). London: Taylor \& Francis.

HALLIDAY, M.A.K. 1973. Explorations in the Functions of Language London: Edward Arnold.

HYMES, D. 1996. Ethnography, linguistics, narrative inequality: Toward an understanding of voice. London: Taylor \& Francis.

IVERSON, S.V., \& JH. JAMES. 2010. Becoming 'effective' citizens? Change-oriented service in a teacher education program. Innovative Higher Education. 35(1), 19-35.

KEMMIS, S., \& R. MCTAGGART. 2005. Participatory action research: Communicative action and the public sphere. In N.K. Denzin \& Y.S. Lincoln (Eds., The Sage handbook of qualitative research ( $3^{\text {rd }}$ ed., pp. 559-604). Thousand Oaks. CA: Sage.

LADSON-BILLINGS, G. 1995. Towards a theory of culturally relevant pedagogy. American Education Research Journal, 32(3), 465-491.

LITCHNER, J.H., \& D. JOHNSON. 1973. Changes in Attitudes toward Negroes by White elementary students after the use of Multi-ethnic Readers. Journal of educational Psychology, 65, 295-299.

MAY, S. 1999. Critical multiculturalism: Rethinking multicultural and antiracist education. Philadelphia; Psychology Press.

MATHISON, S., EW. ROSS \& JW. CORNETT. 1993. Considering Ethical Issues in Fieldwork in Ethical issues in Qualitative Research. City: Qualitative Research SIG, AERA.

MCLAREN, P. 1988. Schooling the Postmodern Body: Critical Pedagogy and the Politics of Enfleshment. Boston journal of Education 170, no 3:53-83.

NORTON, D.E., 1983. Language and cognitive development through multicultural literature. New York, Taylor \& Francis.

RASINSKI, T.V., \& N.D. PADAK. 1990. Multicultural learning through Children's Literature. Language Arts, 67, 576-580. 
SIMS-BISHOP, R. 1997. Selecting literature for a multicultural curriculum. In V.J. Harris (Ed.), Using multi-ethnic literature in the K-8 classroom (pp. 1-19). Norwood, MA: Christopher-Gordon.

STEVENS, L. P., \& T.W. BEAN. 2007. Critical literacy: Context, research, and practice in the K-12 classroom. Thousand Oaks, CA: Sage Publications, Inc.

STREET, B. 1995. Social Literacies Longman; London.

UKPOKODU, O. N. 2008. Teachers' reflection on pedagogies that enhance learning in an online course on teaching for equity and social justice. Journal of Interactive Online Learning, 7(3), 227-255.

VYGOTSKY, L. 1978. Mind in society: The development of higher psychological processes. Cambridge, MA: Harvard University Press.

WAGHID, Y. 2011. On Cavellian scepticism and postgraduate student supervision. South African Journal of Higher Education 25(3): 393-396.

WHITEHEAD, J., \& J. MCNIFF. 2006. Action Research: Living Theory. SAGE, London.

ZUBER-SKERRITT, O. 2012. Action Research in Higher Education. For Improving Learning, Teaching and Research. Workshop in Faculty of Education, Developing Action Research Resource Materials: Stellenbosch.

\section{BIOGRAPHICAL NOTE}

Dr Omar Esau is a Curriculum Studies and Multicultural Education Lecturer at Stellenbosch University. His research interests are in Critical Pedagogy, HIV \& AIDS Education, Teachers as Researchers and Multicultural \& Multi-Religious Education.

Email: oesau@sun.ac.za 